\title{
DOS ARABISMES INTERROMÀNICS
}

\author{
Germà COLÓN DOMÈNECH \\ Universitat de Basilea
}

Participant entre semitistes a l'homenatge que hom ret a María Jesús Rubiera, al qual he estat amablement invitat, poca cosa especifica hi puc aportar. Em permetré tanmateix d'adduir uns materials sobre dos arabismes, els quals tenen o han tingut una projecció major de la que es suposava. Tant pel Nord com pel Sud els dos ètims que ací considere han sobrepassat els límits d'una sola llengua.

\section{Català alfabia - occità fabia, fabi.}

Quan Jaume Mass6 i Torrents va publicar, poc acuradament per cert, la seva edició del Decameron català del 1429, cregué poder determinar-ne la procedencia geogràfica mallorquina del traductor, basant-se en el fet que hi escrivia aygo (per aigua) i en la presencia del mot alfabia 'gerra gran', lexema encara viu a les llles, sobretot sota la forma aufabia'. En un treball meu del 1976 vaig mostrar la feblesa d'aquests i d'altres arguments, tot assenyalant que alfabia era un terme que vivia al conjunt del domini lingüístic català, tant a Mallorca, com a Girona o Valencia ${ }^{2}$. El DECat, sense fer-hi esment, com acostuma, seguí, pero, el meu punt de vista i afegí més documentació del Rosselló

1 Johan Boccaci, Decameron, traducció catalana segons l'únic manuscrit conegut (1429), publicat per Jaume Massó Torrents, New York, 1910, p. Vlll («Bibliotheca Hispanica»).

${ }^{2}$ G. Colón, El léxico catalán en la Romania, Madrid, Gredos, 1976, p. 159; vegeu ara El lèxic català dins la Romània, València, 1993, pp. 138-139. 
treta dels materials d'Alart, ${ }^{3} i$, fidel a la seva proclivitat de veure catalanismes per tot arreu, considerà que les formes dels parlars occitans són preses del català, entre les quals l'exemple de Mistral fabi usat a Calendau.

Malhauradament se li va escapar un ben interessant passatge provençal, reportat pel diccionari de Levy, ${ }^{4}$ tant antic que les mostres catalanes, procedent d'Ièro (francès Hières) i que apareix en un inventari de l'any 1431 del castell d'aquesta localitat del departament del Var. Aixf entre els objectes que són «En la despensa pres de la sala» hi és mencionada:

«tem, una fabia a tenir oli»s.

Els redactors que ara continuen l'elaboració del $F E W$, en estudiar aquests termes occitans, de la Provença estricta, com són els marsellesos i rodanesos fabi, fabieto $i$ fabioun 'gerra, gerreta' elencats al diccionari d'Achard (1785) i a Lou Tresor dóu Felibrige, ${ }^{6}$ no hi van advertir llur relació amb els catalans alfabia, alfabieta, alfabier, alfabió, i collocaren aquells prudentment entre els «Matériaux d'origine inconnue ou incertaines, ${ }^{7}$ en la secció de mots que hom inclou sota el concepte de «cruche», materials que són oferts per una possible identificacio als investigadors.

${ }^{3}$ J. Coromines, Diccionari crític i complementari de la llengua catalana, Barcelona, Curial, 1980, p. 174 (citem: DECat).

${ }^{4}$ E. Levy, Provenzalisches Supplement Wörterbuch, Leipzig,1902, Ill, p. 366, s.v. fabia ("Krug"). El prov. ant. fabia "jarre" també és al Petit dictionnaire provençal-français (s.v.) del mateix autor.

5 Publicat per Maurice Raimbault, «Inventari dou castèu d'lèro en 1431*, Revue des langues romanes, XXXVII, 1893-1894, pp. 302-318, el nostre text a la pàgina 315.

${ }^{6}$ F. Mistral, Lou Tresor dóu Felibrige ou Dictionnaire Provençal-Français, Paris, Delagrave, 1932, p. 1085: «Fabi, s.f. Jarre; Fabieto, s.f. Petite jarre; Fabioun, s.m. Pot de grès où l'on met des anchois».

${ }^{7}$ W. von Wartburg, Französisches Etymologisches Wörterbuch, XXII (2e partie), fasc. 153, Basel, 1993, p. $120 b$. 
Una volta vinculats ací els vocables catalans amb els occitans, ens trobem no pas davant d'un manlleu, sinó d'una extensió major de la base aràbiga, que ara comprèn dues llengues romàniques, tot i que certament es tracta, com tantes altres vegades, d'un «continuum» lexic catalano-occità.

Sobre l'etim aràbic hāābiya 'gerra gran' informa el DECat (loc. cit.) i ja abans Steiger.

\section{Andalús bardomera | marmotera - Català marmota.}

Durant les sovintejades consultes al repertori de privilegis valencians anomenat Aureum Opus ${ }^{9}$ vaig topar en un document del rei Pere el Cerimoniós del 1336 amb la curiosa expressió marmota de fusta, relativa a l'obstrucció que experimenta el riu Guadalaviar amb aquest embalum (possiblement brosses, arbres tallats, canyes $i$ altres escombraries), que el mateix text glossa com a equivalent del llati congeries; millor dit, com que el mot llatí sembla al redactor massa elevat, hi dóna la denominació popular «congeries fuste marmota vulgariter appellata». Vet ací la disposició en qüestió:

"Quod congeries siue marmota de fusta non possit in riuo fieri a ponte de quart usque ad locum vbi assuetum est exaguari et reponi fusta: et quod super hoc possit imponi pena per iusticiam et iuratos.

Petrus dei gratia rex aragonum valentiæ etc. fidelibus suis iusticiis et iuratis civitatis valentiæ salutem et gratiam. Cum preteritorum dispendia cautiores nos reddere debeant ad futura: propterea quod congeries fuste marmota vulgariter appellata: quæ per fluvium de godalauiar ad dictam civitatem valentiæ ducitur: tam in pontibus civitatis quam in aliis multa retroactis temporibus damna intulerit et posset inferre si non curaremus remedium congruum adhibere: iccirco cauta provisione statuimus et mandamus quatenus nullis sit licitum dictam congeriem fuste sive marmotam facere vel ponere in dicto fluuio sive eius litoribus ei propinquis: de loco videlicet in quo situs est pons loci de quart usque ad locum

${ }^{8}$ Arnald Steiger, Contribución a la fonética del hispano-árabe y de los arabismos en el ibero-románico y el siciliano, Madrid, 1932, p 230, $\$ 30$ (Anejo XVII de la RFE).

${ }^{9}$ Aureum opus regalium priuilegiorum ciuitatis et regni Valentie, ed. Lluís de Alanya, València 1515 (= reprint d'Anubar, València, 1972). 
ubi assueta est ipsa fusta de dicto flunio extrahi et in terram reponi siue exaguari. Et vt predicta melius obseruentur volumus ac vobis mandamus et potestatem plenariam impartimur quod vos possitis contra facientibus penas imponere et eas publicatas exhigere alias compulsiones facere prout vobis videbitur expedire. Datum cesar auguste tertio calendas aprilis anno Domini M.CCCXXXVI ${ }^{10}$.

El nom de l'animal marmota és molt més modern en les llengues hispàniques (ni en català ni en castellà és atestat abans del segle XVIII), calia cercar allondres l'origen d'aquesta marmota que patia el riu Guadalaviar.

Feliçment Robert Pocklington va publicar fa uns any un preciós article, on entre altres arabismes, ${ }^{11}$ estudiava el parell bardomera $i$ marmotera "broza y suciedad que traen los ríos sobre su corriente en las avenidas" en les comarques de l'Andalusia oriental i de Múrcia ${ }^{12}$. Hi té en compte frases com quitar, limpiar la bardomera "desbrozar para que corra el agua". Al costat de bardomera i del primitiu bardoma, hi ha molts punts amb els lexemes marmotera i marmota. A la pàgina 64, Pocklington cartografia aquests lexemes marcant gràficament les variants: l'àmbit geogràfic en són les provincies andaluses de Jaén, Granada i Almeria i la regió de Múrcia, amb Oriola. Ens afecten especialment els exemples murcians, en particular aquest de les Actas Capitulares del Concejo de Murcia del 1467:

«El ryo Segura que pasa por ante esta çibdad esta ribierto en muchos logares de muchos alamos caydos e marmotas e cañares, de manera que al tienpo de las creçidas del el agua non puede despedir; antes por cabsa de lo susodicho el agua regolfa e por ello la huerta e esta çibdad esta en grand peligro. Por esta rason, que la paresçia quel dicho rio se deuia mandar linpiar ${ }^{13}$.

${ }^{10}$ Aureum opus, fol. XCIIII v ${ }^{\circ}$-XCV (= reprint, pp. 248-249).

${ }^{11}$ Robert Pocklington, "Seis voces de origen árabe», Revista de Filología Española, LXV, 1985, pp. 51-74.

${ }^{12}$ Pocklington, $O p$, cit. 58-67. Aquí resta demostrat que bardoma no és aragonès ni té res a veure amb bardo "barro", com suposava el $D E C H, I, p .51$ 2a (s v. bardo, II).

${ }^{13}$ Transcripció de Pocklington, op. cit., p. 65. També el murcià Francisco Cascales (1621) parla de les uramas y marmotas, como suelen (sc. tener) los ríos grandes en sus avenidas». Vegeu J. García Soriano, Vocabulario del dialecto 
Al meu parer tant marmota com bardoma -llurs derivats marmotera, barbotera, marmote, mormote, esmarmotar, bardomar ${ }^{14}$ tenen el mateix origen, el qual es pot explicar per metàtesis o transposicions, pero no sembla massa encertat anar a cercar un ètim aràbic per bardoma i un altre per marmota, si tenim en compte l'estructura sil-labica dels mots i el fenomen d'equivalència acústica. L'autor parteix, sempre amb molta precaució, per bardoma del participi passiu femení mardūma del verb àrab radama 'taponar, obstruir o cegar con tierra', mentre que per marmota, pensa en marbüța, també participi passiu femení de l'arrel r-b-t 'atar, sujetar, frenar' ${ }^{15}$. No obstant ell mateix es planteja la possibilitat -la qual rebutja- que tant bardomera com marmotera hagin pogut eixir d'un mateix ètim.

Pocklington acaba la seua acurada exposició demanant-se si en l'esdevenidor caparecerá en los archivos un antiguo marmota, desde el cual se derivó y difundió la voz marmotera $/-a{ }^{16}$. Els arxius valencians ens han ofert un testimoni de marmota del 1336, doncs el més antic de tots. No pense que el lexema s'hagi estès des de València cap al Sud, pero sí que podem dir que aquest va més enllà de l'àmbit lingüŕstic castella i que abraçà un dia la part meridional del domini català.

murciano, Madrid, 1932, p 81 (s.v marmota).

${ }^{14}$ García Soriano, op. cit, p. 138 esmenta un document del rei Alfons $\mathrm{X}$ de Castella referit a Oriola, on es diu d'una séquia que no se bardome "no s'obstruesca".

${ }^{15}$ Pocklington, op. cit., pp. 61-62 i 65.

${ }^{16}$ Ibidem, p. 67. 